\title{
Femoral Footprint for Anatomical Single-Bundle Anterior Cruciate Ligament Reconstruction: A Cadaveric Study
}

\author{
Young-Mo Kim, MD, Yong-Bum Joo, MD, Ki-Young Lee, MD, and Sung-Jin Hwang, MD \\ Department of Orthopedic Surgery, Chungnam National University School of Medicine, Daejeon, Korea
}

Purpose: To identify the femoral footprint of the anterior cruciate ligament (ACL) in Koreans.

Materials and Methods: Eighteen embalmed cadaveric knees (mean age, 70 years) were examined. First, the shape of the ACL was determined macroscopically. After the ACL femoral footprint was defined, the ACL was cut from the femur and a Kirschner wire was inserted into the center of the ACL, and the position was verified with a C-arm. The position was quantified on the C-arm field using the quadrant method. The length and width of the ACL were measured.

Results: Macroscopically, the ACL is a flat single bundle with an average length of $34 \mathrm{~mm}$ and an average width of $9 \mathrm{~mm}$. On average, the center of the ACL insertion site measured with the quadrant method was positioned at $29.5 \% \pm 2.8 \%$ in an anterior direction (from posterior), and at $38.5 \% \pm 3.2 \%$ in a distal direction (from Blumensaat's line). The anterior and posterior margins of the ACL femoral footprint were the resident's ridge and the cartilage margin of the lateral femoral condyle, respectively.

Conclusions: The center of the ACL femoral footprint is positioned more anteriorly and distally than the positions identified in previous studies.

Keywords: Knee, Anterior cruciate ligament, Reconstruction

\section{Introduction}

An anterior cruciate ligament (ACL) injury is the most common sports-related knee injury, with an annual incidence of 8.1 per 100,000 in the United States ${ }^{1)}$. Studies on anterior cruciate ligament reconstruction (ACLR) have revealed that instability can recur following non-anatomical $\mathrm{ACLR}^{2)}$, and that anatomical ACLR leads to more successful clinical outcomes ${ }^{3-11)}$. However,

Received July 27, 2017; Revised (1st) November 27, 2017;

(2nd) December 22, 2017; Accepted January 5, 2018

Correspondence to: Yong-Bum Joo, MD

Department of Orthopedic Surgery, Chungnam National University

School of Medicine, 266 Munhwa-ro, Jung-gu, Daejeon 35015, Korea

Tel: +82-42-338-2482, Fax: +82-42-338-2480

E-mail: longman76@hanmail.net

Source of funding: This research was supported by Chungnam National University Research Fund.

This is an Open Access article distributed under the terms of the Creative Commons Attribution Non-Commercial License (http://creativecommons.org/licenses/by-nc/4.0/) which permits unrestricted non-commercial use, distribution, and reproduction in any medium, provided the original work is properly cited. many questions remain regarding the femoral footprint of the ACL, and the appropriate location of the anatomical tunnel for anatomical ACLR remains controversial. Certain methods can be used for an accurate evaluation of the ACL footprint. One of the most popular methods is the quadrant method, introduced by Bernard et al. ${ }^{12)}$. In this method, grid placement on the lateral wall of the femoral intercondylar notch is determined using Blumensaat's line. Blumensaat's line is a line that corresponds to the roof of the intercondylar fossa of the femur, as seen on a lateral radiograph of the knee. Bernard et al. ${ }^{12)}$ defined Blumensaat's line as a straight line. Anatomical studies on the ACL have suggested that the bony femoral ACL insertion is in the shape of a crescent, and that the resident's ridge (lateral intercondylar ridge) and posterior cartilage of the lateral femoral condyle serve as the anterior and posterior margins of the ACL femoral footprint, respectively ${ }^{13-17)}$. In addition, it has been suggested that the ACL femoral footprint varies in shape, and can be circular, elliptical, kidneyshaped, trapezoidal, ovoid, and triangular ${ }^{18)}$. In a 2012 systematic review of the literature on the ACL femoral footprint, Piefer et al. ${ }^{19)}$ reported that the mean center of the ACL footprint was at 
$28.5 \% \times 35.2 \%$ using the quadrant method ${ }^{12)}$. While this observation is an important standard for anatomical single-bundle ACLR, most studies have been performed on Westerners, with very few focusing on Koreans. Thus, we conducted a cadaveric study in Koreans to determine clear anatomical reference points for the ACL femoral footprint, which can be used for designing the femoral tunnel during anatomical single-bundle ACLR. For this purpose, we assessed the shape and location of the ACL femoral footprint and its relationships with other bony landmarks.

\section{Materials and Methods}

Eighteen embalmed knees from 21 human cadavers, used in an anatomy course for medical students, were studied. Cadavers with a history of knee surgery or trauma were excluded. Cadavers were fixed in 5\% formaldehyde. Only a single knee was used for dissection from each pair of cadaveric knees. The 18 knees studied were from 10 females and 8 males. The mean age was 70 years and ranged from 55 to 86 years. Nine right knees and nine left knees were used. All dissections and markings were performed by one senior author (YBJ).

\section{Cadaveric Dissection}

After removing nearby soft tissues and surrounding structures, the knee joint was isolated by cutting the femur and tibia at 20 $\mathrm{cm}$ above and below the joint using an oscillating saw. After removing soft tissues except for the ACL, the shape of the ACL was observed. Subsequently, the ACL was excised from its tibial insertion. Using an oscillating saw, the dissection was made 1-2 $\mathrm{mm}$ medially from the highest point of the anterior outlet of the intercondylar notch to reveal the femur lateral wall, which was recognized as the femoral insertion site of the ACL. Good visualization of the ACL bundle at the lateral femoral condyle was confirmed (Fig. 1).

\section{Evaluation of the ACL Footprint in Relation to Bony Landmarks}

The specimens were assessed macroscopically to determine the overall positional relation of the ACL insertion to Blumensaat's line, the posterior femoral cortex, and the cartilage of the lateral femoral condyle (Fig. 2).

Anteromedial (AM) and posterolateral (PL) bundles of the ACL are usually identified by differences in tension patterns during knee range of motion. However, in our study, the ACL was observed as a slightly flat single bundle, and it was difficult to distinguish AM and PL bundles. Therefore, we regarded the ACL as a single bundle. The ACL femoral footprint was defined and cut from the femur, and the center point was visually defined and marked with a $1.6 \mathrm{~mm}$ Kirschner wire. Next, the length and width of the ACL were measured. The width of the ACL was taken as the length of its widest part. Next, radiological films were obtained using a $\mathrm{C}$-arm intensifier. The center of the ACL femoral footprint was identified on the $\mathrm{C}$-arm image using the quadrant method. Based on the quadrant method, it was aligned with the line connecting the anterior and posterior points of the cartilage of the lateral femoral condyle, and the length was measured. The location was quantified with reference to the intersection of the line connecting the anterior and posterior points of the cartilage of the lateral femoral condyle cartilage and posterior femoral cortex line. The position of the ACL femoral footprint was defined as a percentage ratio of the sagittal diameter of the lateral condyle measured along Blumensaat's line ${ }^{12)}$ (Fig. 3).
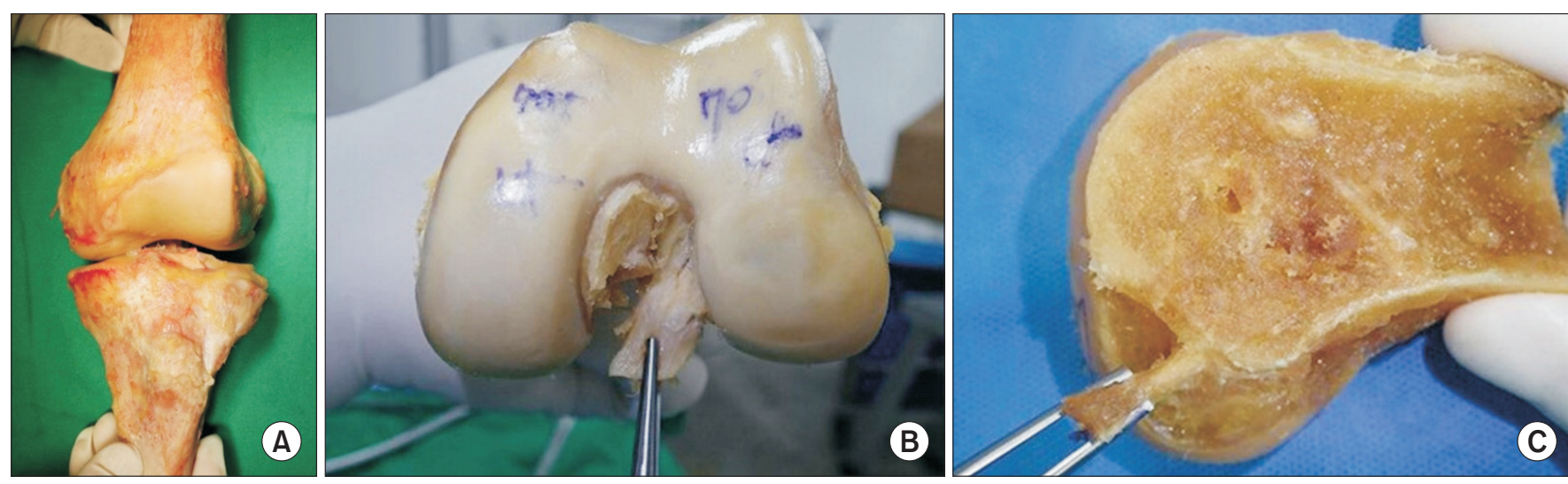

Fig. 1. Gross photo of a 60 -year-old female cadaver. (A) Soft tissues and other structures except for the anterior cruciate ligament (ACL) were removed. (B) The ACL was removed from its tibial attachment. (C) Sagittal dissection was performed 1-2 mm medial from the center of the femoral intercondylar notch using an oscillating saw. The ACL main bundle, held with forceps, appeared as a single, flat bundle. 

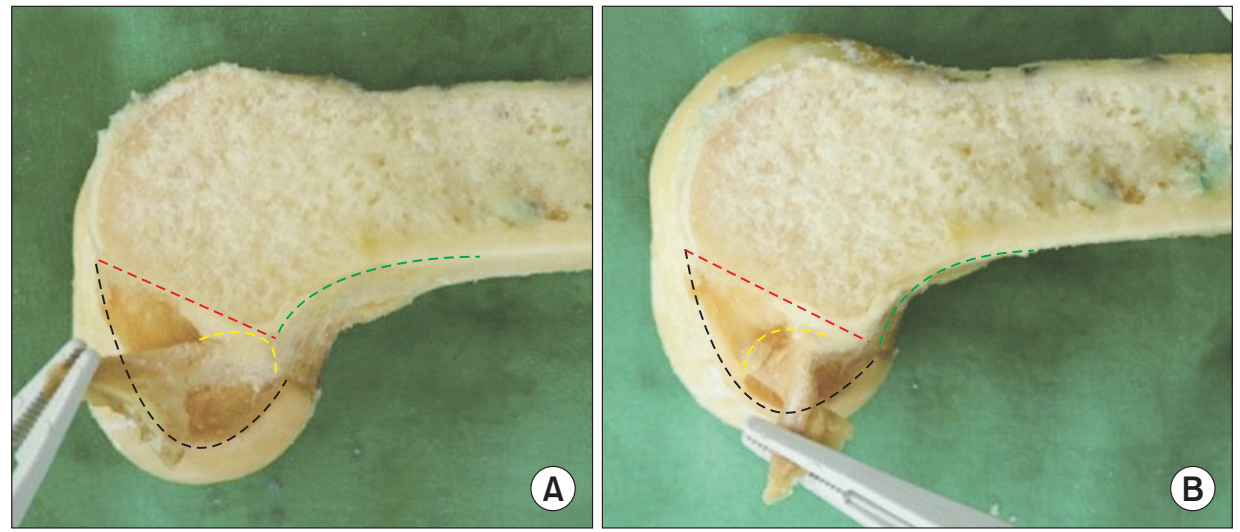

Fig. 2. The anterior cruciate ligament (ACL) femoral insertion site (yellow dotted line) was observed by moving the ACL in anterior, posterior, proximal, and distal directions. The ACL was pulled anteriorly and distally (A) and posteriorly (B). Blumensaat's line (red dotted line), cartilage of the lateral femoral condyle (black dotted line), and the posterior femoral cortex (green dotted line) are shown.

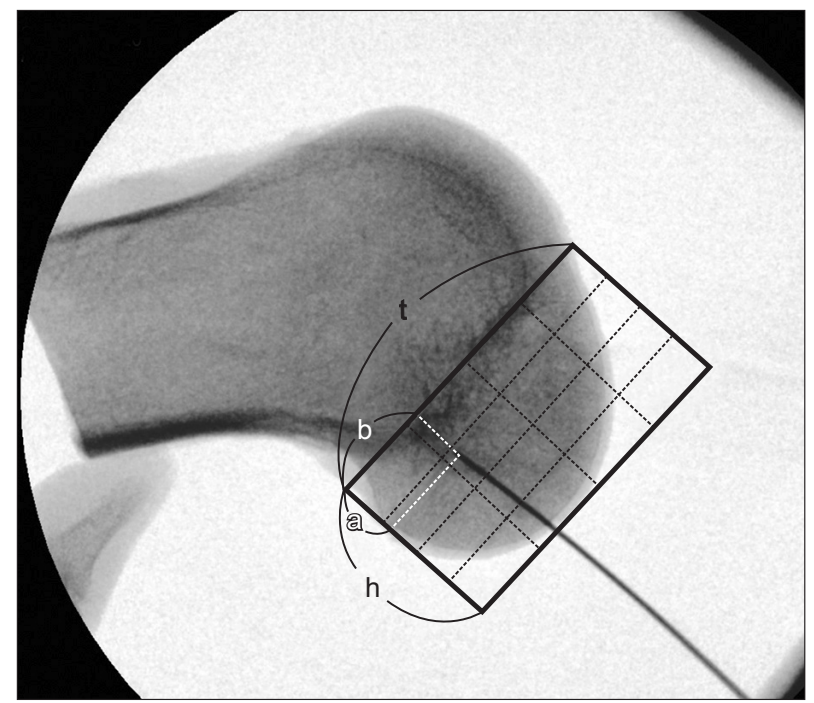

Fig. 3. Quadrant method as described by Bernard et al. ${ }^{12)}$. t: total sagittal distance of the lateral femoral condyle along Blumensaat's line, h: intercondylar notch height, a: distance of the center of the anterior cruciate ligament (ACL) footprint from the deepest subchondral contour, b: distance of the center of the ACL footprint from Blumensaat's line.

\section{Results}

Macroscopically, the ACL was observed as a slightly flat single bundle, and the AM and PL bundles were not clearly distinguishable. The average length of the ACL was $34 \mathrm{~mm}$ (range, 26 to 36 $\mathrm{mm}$ ) and the average thickness was $9 \mathrm{~mm}$ (range, 6 to $15 \mathrm{~mm}$ ). In the radiographic evaluation, the center of the femoral ACL footprint was placed at $29.5 \% \pm 2.8 \%$ in an anterior direction (from posterior) and at $38.5 \% \pm 3.2 \%$ in a distal direction (from Blumensaat's line) (Table 1, Fig. 3). The anterior margin of the femoral footprint of the ACL matched the resident's ridge. Blumensaat's line formed the roof of the femoral footprint of the ACL. The posterior margin matched the cartilage margin of the lateral femoral condyle.
Table 1. Average Anterior Cruciate Ligament (ACL) Femoral Footprint Measured Using the Quadrant Method

\begin{tabular}{|c|c|c|c|c|}
\hline Case & $\mathrm{a} / \mathrm{t}$ & $\mathrm{b} / \mathrm{h}$ & Age (yr) & Sex \\
\hline 1 & 31.5 & 41.5 & 60 & $\mathrm{~F}$ \\
\hline 2 & 29 & 37.7 & 64 & $\mathrm{~F}$ \\
\hline 3 & 33 & 42 & 77 & M \\
\hline 4 & 34.5 & 43.2 & 55 & $\mathrm{~F}$ \\
\hline 5 & 28.8 & 35.5 & 79 & M \\
\hline 6 & 26.6 & 34.3 & 81 & $\mathrm{~F}$ \\
\hline 7 & 35 & 42.6 & 85 & M \\
\hline 8 & 26 & 33.9 & 60 & M \\
\hline 9 & 27.5 & 36.6 & 58 & $\mathrm{~F}$ \\
\hline 10 & 27 & 32.4 & 75 & $\mathrm{~F}$ \\
\hline 11 & 29.5 & 39.2 & 77 & $\mathrm{~F}$ \\
\hline 12 & 30.2 & 40.6 & 65 & $\mathrm{~F}$ \\
\hline 13 & 28.4 & 38.5 & 67 & M \\
\hline 14 & 25 & 36.5 & 59 & M \\
\hline 15 & 31.3 & 41.5 & 60 & $\mathrm{~F}$ \\
\hline 16 & 28.7 & 38 & 86 & $\mathrm{~F}$ \\
\hline 17 & 29.5 & 40.5 & 82 & M \\
\hline 18 & 29.5 & 38.5 & 70 & M \\
\hline Average & $29.5 \% \pm 2.8 \%$ & $38.5 \% \pm 3.2 \%$ & 70 & \\
\hline
\end{tabular}

a: distance of the center of the ACL footprint from the deepest subchondral contour, $t$ : total sagittal distance of the lateral femoral condyle along Blumensaat's line, b: distance of the center of the ACL footprint from Blumensaat's line, h: intercondylar notch height.

\section{Discussion}

The placement of the femoral tunnel using the femoral ACL footprint is a decisive factor in the outcome of anatomical singlebundle ACLR. Multiple studies have reported that more vertical femoral tunnels are associated with rotatory instability, and nonanatomical tunnel placement is associated with pain and instabil- 
ity $^{20,21)}$.

Bernard et al. ${ }^{12)}$ utilized the quadrant method to evaluate the position of the ACL femoral footprint using a lateral radiograph, and reported that the center of the ACL femoral footprint was $24.8 \%$ in the percentage of $a / t$ (distance of the center of the ACL footprint from the deepest subchondral contour/total sagittal distance of the lateral femoral condyle along Blumensaat's line) and $28.5 \%$ in the percentage of $\mathrm{b} / \mathrm{h}$ (distance of the center of the ACL footprint from Blumensaat's line/intercondylar notch height) (Fig. 3). Piefer et al. ${ }^{19)}$ published a systematic review on the center of the ACL footprint. They calculated the mean anatomic centrum, defined as a point equidistant between the AM and PM bundle, by use of the following formula: [(AM bundle parallel to Blumensaat's line+PL bundle parallel to Blumensaat's line)/ 2 by (AM bundle perpendicular to Blumensaat's line+PL bundle perpendicular to Blumensaat's line)/2)]. Colombet et al. ${ }^{13)}$ reported that the center of the femoral ACL footprint was placed at $29.35 \%$ in an anterior direction and at $36.45 \%$ in a distal direction $(29.35 \% \times 36.45 \%)$. Iriuchishima et al. ${ }^{22)}$ reported that the center of the femoral ACL footprint was placed at $23.5 \% \times 39 \%$. Forsythe et al. ${ }^{23}$ ) reported that the center of the femoral ACL footprint was placed at $28.4 \% \times 44.25 \%$. According to Piefer et al. ${ }^{19)}$, the mean center of the ACL footprint was at $28.5 \% \times 35.2 \%$. The ACL footprint determined in the current study was placed at $29.5 \% \times 38.5 \%$, which was more anterior and distal to that found in previous studies. This location can constitute a new interpretation of the center of the ACL footprint that could aid in anatomical single-bundle ACLR.

In this study, we confirmed that the center of the ACL footprint is located between the resident's ridge, the anterior margin of the ACL, the cartilage margin of the lateral femoral condyle, and the posterior border of the ACL, consistent with previous studies ${ }^{13-17)}$. The main limitations of this study were as follows: 1) ACL dissection was performed based on macroscopic evaluation. Notwithstanding meticulous precautions, there was a possibility of human error and bias. 2) We had a relatively small sample size. A larger sample is required to shed light on anatomical variation and accurate ACL anatomy. 3) The ACL footprint was assessed using a two-dimensional technique. The ACL is attached to the bone three-dimensionally; therefore, a three-dimensional technique is required to assess it. 4) A biomechanical study is needed to substantiate the graft strength when the tunnel is formed on the ACL center. 5) We did not perform histologic studies.

\section{Conclusions}

This study is a detailed anatomical study on the ACL femoral footprint. The main functional fiber of the ACL was observed as a single bundle. The ACL footprint is positioned at the space formed by the resident's ridge, the cartilage margin of the lateral femoral condyle, and Blumensaat's line. The center of this footprint could serve as a reference point for femoral tunnel formation during anatomical single-bundle ACLR.

\section{Conflict of Interest}

No potential conflict of interest relevant to this article was reported.

\section{References}

1. Clayton RA, Court-Brown CM. The epidemiology of musculoskeletal tendinous and ligamentous injuries. Injury. 2008;39:1338-44.

2. Marchant BG, Noyes FR, Barber-Westin SD, Fleckenstein C. Prevalence of nonanatomical graft placement in a series of failed anterior cruciate ligament reconstructions. Am J Sports Med. 2010;38:1987-96.

3. Fu FH, van Eck CF, Tashman S, Irrgang JJ, Moreland MS. Anatomic anterior cruciate ligament reconstruction: a changing paradigm. Knee Surg Sports Traumatol Arthrosc. 2015;23:640-8.

4. Lim HC, Yoon YC, Wang JH, Bae JH. Anatomical versus non-anatomical single bundle anterior cruciate ligament reconstruction: a cadaveric study of comparison of knee stability. Clin Orthop Surg. 2012;4:249-55.

5. Amis AA, Dawkins GP. Functional anatomy of the anterior cruciate ligament: fibre bundle actions related to ligament replacements and injuries. J Bone Joint Surg Br. 1991;73:2607.

6. Loh JC, Fukuda Y, Tsuda E, Steadman RJ, Fu FH, Woo SL. Knee stability and graft function following anterior cruciate ligament reconstruction: comparison between 11 oclock and 10 o'clock femoral tunnel placement: 2002 Richard O’Connor Award paper. Arthroscopy. 2003;19:297-304.

7. Zavras TD, Race A, Amis AA. The effect of femoral attachment location on anterior cruciate ligament reconstruction: graft tension patterns and restoration of normal anteriorposterior laxity patterns. Knee Surg Sports Traumatol Arthrosc. 2005;13:92-100. 
8. Karlsson J, Irrgang JJ, van Eck CF, Samuelsson K, Mejia HA, $\mathrm{Fu}$ FH. Anatomic single- and double-bundle anterior cruciate ligament reconstruction, part 2: clinical application of surgical technique. Am J Sports Med. 2011;39:2016-26.

9. Kondo E, Yasuda K, Azuma H, Tanabe Y, Yagi T. Prospective clinical comparisons of anatomic double-bundle versus single-bundle anterior cruciate ligament reconstruction procedures in 328 consecutive patients. Am J Sports Med. 2008; 36:1675-87.

10. Yagi M, Wong EK, Kanamori A, Debski RE, Fu FH, Woo SL. Biomechanical analysis of an anatomic anterior cruciate ligament reconstruction. Am J Sports Med. 2002;30:660-6.

11. Yasuda K, Kondo E, Ichiyama H, Tanabe Y, Tohyama H. Clinical evaluation of anatomic double-bundle anterior cruciate ligament reconstruction procedure using hamstring tendon grafts: comparisons among 3 different procedures. Arthroscopy. 2006;22:240-51.

12. Bernard M, Hertel P, Hornung H, Cierpinski T. Femoral insertion of the ACL: radiographic quadrant method. Am J Knee Surg. 1997;10:14-21.

13. Colombet P, Robinson J, Christel P, Franceschi JP, Djian P, Bellier G, Sbihi A. Morphology of anterior cruciate ligament attachments for anatomic reconstruction: a cadaveric dissection and radiographic study. Arthroscopy. 2006;22:984-92.

14. Duthon VB, Barea C, Abrassart S, Fasel JH, Fritschy D, Menetrey J. Anatomy of the anterior cruciate ligament. Knee Surg Sports Traumatol Arthrosc. 2006;14:204-13.

15. Ferretti M, Ekdahl M, Shen W, Fu FH. Osseous landmarks of the femoral attachment of the anterior cruciate ligament: an anatomic study. Arthroscopy. 2007;23:1218-25.

16. Markatos K, Kaseta MK, Lallos SN, Korres DS, Efstathopoulos N. The anatomy of the ACL and its importance in ACL reconstruction. Eur J Orthop Surg Traumatol. 2013;23:74752.

17. Shino K, Suzuki T, Iwahashi T, Mae T, Nakamura N, Nakata $\mathrm{K}$, Nakagawa $\mathrm{S}$. The resident's ridge as an arthroscopic landmark for anatomical femoral tunnel drilling in ACL reconstruction. Knee Surg Sports Traumatol Arthrosc. 2010;18: 1164-8.

18. Zauleck MK, Gabriel S, Fischmeister MF, Hirtler L. Origin of the anterior cruciate ligament and the surrounding osseous landmarks of the femur. Clin Anat. 2014;27:1103-10.

19. Piefer JW, Pflugner TR, Hwang MD, Lubowitz JH. Anterior cruciate ligament femoral footprint anatomy: systematic review of the 21st century literature. Arthroscopy. 2012;28:87281.

20. Giron F, Buzzi R, Aglietti P. Femoral tunnel position in anterior cruciate ligament reconstruction using three techniques: a cadaver study. Arthroscopy. 1999;15:750-6.

21. Kaseta MK, DeFrate LE, Charnock BL, Sullivan RT, Garrett WE Jr. Reconstruction technique affects femoral tunnel placement in ACL reconstruction. Clin Orthop Relat Res. 2008;466:1467-74.

22. Iriuchishima $T$, Ingham SJ, Tajima $G$, Horaguchi $T$, Saito A, Tokuhashi Y, Van Houten AH, Aerts MM, Fu FH. Evaluation of the tunnel placement in the anatomical double-bundle ACL reconstruction: a cadaver study. Knee Surg Sports Traumatol Arthrosc. 2010;18:1226-31.

23. Forsythe B, Kopf S, Wong AK, Martins CA, Anderst W, Tashman S, Fu FH. The location of femoral and tibial tunnels in anatomic double-bundle anterior cruciate ligament reconstruction analyzed by three-dimensional computed tomography models. J Bone Joint Surg Am. 2010;92:1418-26. 